\title{
Review on the prevalence, risk factors and disease Management of Hypertension among floating population in China during 1990-2016
}

\author{
Lina Su, Long Sun and Lingzhong $\mathrm{Xu}^{*}$
}

\begin{abstract}
s
Objective: To have a basic and comprehensive understanding about the prevalence, risk factors and disease management situation of hypertension among floating population in China.

Method: We used "(hypertension or hypertensive or chronic disease) and (floating population or migrant worker)" as the key words, to search in the China academic literature database (CNKI), Wan Fang database, PubMed and Web of Science for relevant literature and extracted the data about the prevalence of hypertension, relevant risk factors and disease management of floating population in China from 1990 to 2016.

Result: The 23 related studies that entered into final analysis were all articles in Chinese. The prevalence of hypertension in floating population is lower than that in both general population and local residents. The prevalence of hypertension in male floating population is higher than that in females. In addition, the prevalence of hypertension also increases with age growing. As for the risk factors of hypertension, the rate of drinking in floating population is higher than that in general population and local residents, while the rates of overweight and obesity in floating population are lower than that in general population in China. Finally, the rates of awareness, treatment and control of hypertension are also lower in floating population.

Conclusion: The major problem of floating population is focused on their unhealthy lifestyle (drinking) and deficient disease management. Therefore, we should increase the fund and facility support for public health service system so as to improve their service delivery ability, and enforce the education and unhealthy lifestyle intervention to improve their health awareness and compliance to disease management.
\end{abstract}

Keywords: Hypertension, Floating population, Risk factor, Disease management

\section{Background}

Floating population is a special group coming with the rapid development of economy and urbanization in China, mainly refers to the adults at the childbearing age who leave their domicile for the purpose of making a living [1]. According to the new statistics, the number of floating population in China has already reached 247 million [2]. Because of low-level education, heavy work and poor living condition, the health status of floating

\footnotetext{
* Correspondence: Izxu@sdu.edu.cn

School of Public Health, Department of Social Medicine and Health Management, Shandong University, No.44, Culture west road, Lixia District, Jinan 250012, Shandong Province, China
}

population is always suboptimal, and the prevalence of chronic disease is at a high level [3]. Meanwhile, there also exists vast disparities of health insurance coverage and health service utilization between floating population and local residents, most of the floating population have no timely access to primary or some other kinds of health care service which cause the poor control of chronic diseases.

Hypertension, as one of the major chronic disease, is not only the direct cause of health loss, but also a major and independent risk factor of other cardiovascular diseases including coronary heart disease, heart failure and stroke. Due to the incomplete monitoring system,it is

(c) The Author(s). 2018 Open Access This article is distributed under the terms of the Creative Commons Attribution 4.0 International License (http://creativecommons.org/licenses/by/4.0/), which permits unrestricted use, distribution, and reproduction in any medium, provided you give appropriate credit to the original author(s) and the source, provide a link to the Creative Commons license, and indicate if changes were made. The Creative Commons Public Domain Dedication waiver (http://creativecommons.org/publicdomain/zero/1.0/) applies to the data made available in this article, unless otherwise stated. 
quite difficult for the management of those hypertensive patients in floating population because of the lack of relevant data about prevalence, risk factors and disease management of hypertension in floating population. Therefore, this review was designed to focus on the prevalence, risk factor and disease management of hypertension among floating population in China, so as to provide some references for improvement measures.

\section{Method}

\section{Data sources}

A systematic search was performed using China academic literature (CNKI), Wan Fang, PubMed and Web of Science databases across the period 1990-2016 to identify relevant researches. Search terms used either singularly or in combination were "hypertension", "hypertensive", "chronic disease", "floating population" and "migrant worker" in the thesaurus and index lists of the relevant databases in both Chinese and English words. Also "free text" words were used to supplement the search terms [medical subject heading (MeSH) search terms in the case of Medline]. Manual searches of the bibliographies of searched articles and reviews in the field were also conducted.

\section{Study selection}

The inclusion criteria: (1) randomized clinical trials, prospective and retrospective observational studies; (2) published as original articles in scientific journals; (3) research objects are floating population. The exclusion criteria: (1) review article, questionnaire reliability and validity research; (2) non-Chinese Mainland floating population; (3) the lack of related data. The information table was designed by the research team, and the information was extracted by 2 researchers. The opinions were decided by the task group when the opinions were extracted.

\section{Quality check}

Literature evaluation criteria recommended by the Agency for Healthcare Research and Quality (AHRQ) in the United States were used to evaluate the cross-sectional study quality [4]. The scale consisted of 11 items, including subjects, selection, research, quality control and data processing, using the "yes", "no" and "unclear" as answers. The quality evaluation was conducted independently by 2 researchers (Lina Su, graduate student, majored in health management. Long Sun, doctor, majored in suicidology), and the decision was made by the senior researcher (Lingzhong $\mathrm{Xu}$, professor, majored in health economy) when differences occurred.

\section{Results}

\section{Incorporation of literature}

The numbers of initial retrieval in the CNKI, Wan Fang data, PubMed, and the Web of Science were 12, 29, 10 and 16 respectively, and the final sample included 23 studies (Fig. 1). Subjects of the studies were distributed in different regions in China, different level units such as the provinces, municipalities and districts were included.

\section{Literature quality evaluation}

As can been seen from Table 1, all the studies were conducted between 2010 and 2016, and the locations of subjects were distributed in different provinces, autonomous regions and municipalities in Mainland China. Among those selected studies, 1 study was conducted in the whole country, 8 studies in the administrative regions of province, 4 studies in the administrative regions of municipality and 10 studies in the administrative of district. The sample size ranged from 162 to 48,704. The scores of the included studies judged by the cross-sectional study quality evaluation criteria recommended by AHRQ show that they all have relatively good quality.

\section{The prevalence of hypertension in the floating population and comparison with general population}

According to a national survey conducted in China, $33.7 \%$ of Chinese adults were hypertensive patients [5].When it comes to the floating population, the prevalence of hypertension varies in different areas in China (Table 2). By comparison, we could find that except for the study in Inner Mongolia Province (36.5\%) [6], most results show that the prevalence of hypertension in floating population is lower than that in national population in China. However, no study has done further analysis of the reasons for the difference. And the regions with higher prevalence of hypertension within the floating population are Hebei Province (27.00, 28.05 and 25.78\%) [7-9] and Baohe district of Anhui Province (31.6\%) [10], which are mainly located in the north of Mainland China. Through the analysis of those included studies, we also could find it shows a slight decreasing tendency in the prevalence of hypertension from north to south in China (Fig. 2).

In addition, while the prevalence of hypertension in most studies are in the similar level, there also exist some inconsistent results in the same province. For example, the prevalence of hypertension in Zhongning county of Ningxia Province is only $7.3 \%$ [11], which is quite different from the research conducted by Yine Zhang in Ningxia Province (15.57\%) [12]; and the prevalence in Kashi City of Xinjiang Province is $8.00 \%$ [13], lower than the prevalence of Akesu City of Xinjiang Province (25.31\%) [14]'in Xiuyun Sun's study [15], the 


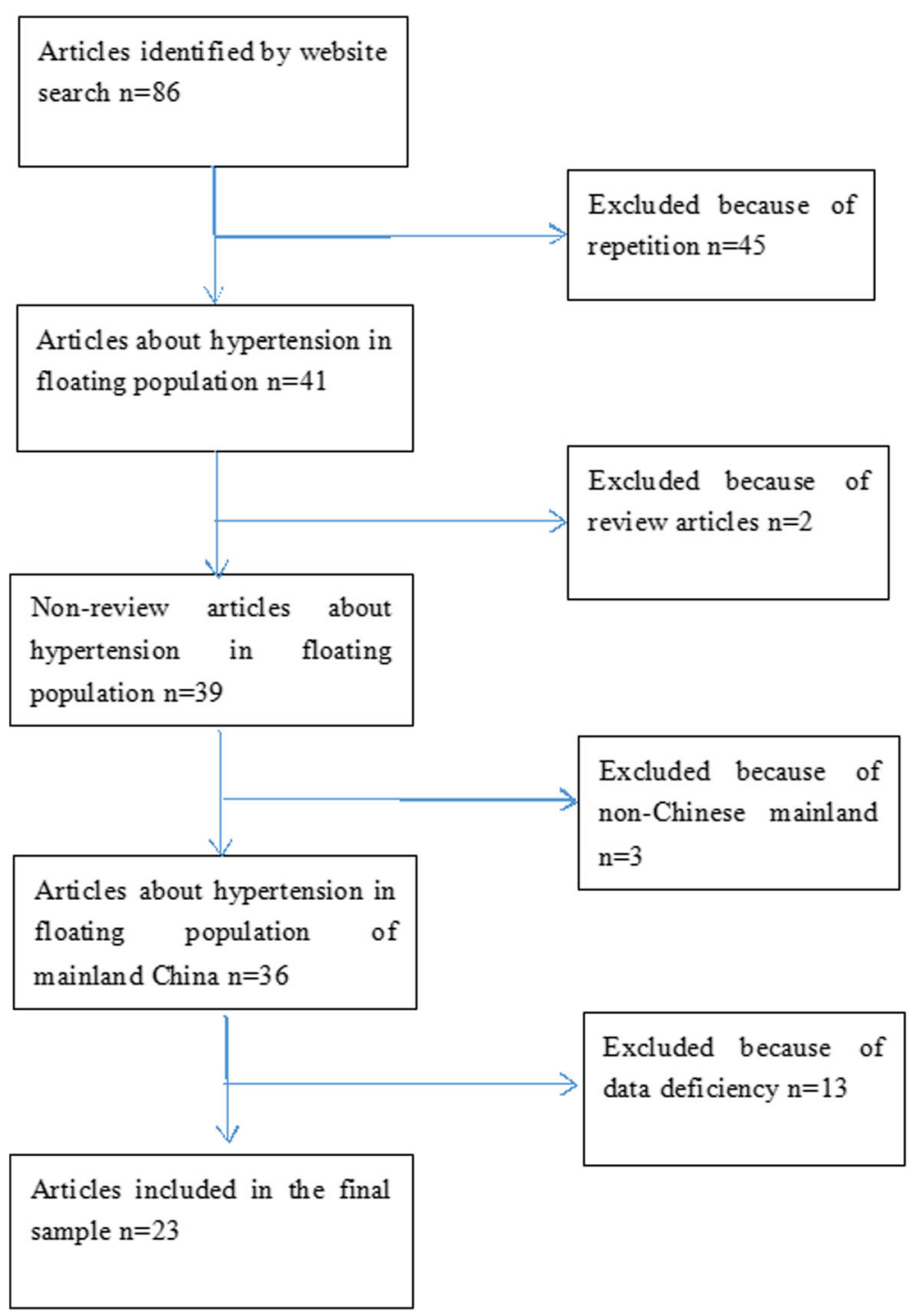

Fig. 1 Quorum flow chart

prevalence in Chongwen District in Beijing City is $8.70 \%$, which is also lower than the result of Lei Qiao's result in Beijing (21.20\%) [16]. Moreover, the prevalence in Chuanhua Yu's study is $22.7 \%$ in Hubei Province [17], while it is only $16.5 \%$ in Tianjing He's research [18]. This phenomenon might be attributed by the problem of sample selection.

\section{Comparison with local population}

To find out the influencing factors of hypertension in floating population, a comparison of the prevalence between floating population and local residents is of great importance. Most studies show that the prevalence of hypertension in floating population is lower. In Hebei Province, the prevalence of hypertension in employed floating population is lower than that in local residents
$(27.86 \%)$ [8, 9]. Similar results can also be found in Hubei Province [17, 18], Ningxia Province [12, 19], Jiangxi Province [20] and Akesu City [14]. However, Qian Zhou's study obtains an opposite result that the prevalence of hypertension in floating population in Inner Mongolia is higher than that in local residents above 15 years old in Hohhot City [6]. The inconsistence in results might be explained by the difference in demographic characteristics.

Researchers find that the deficient utilization of primary health service in floating population is also a notable problem. Xiuyun Sun's study shows that the percentage of floating population who utilise the community health service is only $33.40 \%$ in Beijing [15], and the rate of community management of hypertension in floating population is $2.30 \%$ in Hunan Province [21], 
Table 1 Quality evaluation of included literature

\begin{tabular}{|c|c|c|c|c|c|}
\hline First author & Published year & Sample size & Study area & Research type & Quality score \\
\hline Xin Meng [24] & 2015 & 1493 & Jilin province & provincial & 6 \\
\hline Tao Li [14] & 2013 & 162 & Akesu city,Xinjiang province & municipal & 6 \\
\hline Xiaofei Wu [13] & 2013 & 300 & Kashi city, Xinjiang province & municipal & 4 \\
\hline Qian Zhou [6] & 2015 & 1500 & Inner Mongolia province & provincial & 8 \\
\hline Chunxia Liu [7] & 2015 & 303 & Haigang district, Qinghuangdao city & district & 6 \\
\hline Chunxia Liu [8] & 2015 & 300 & Haigang district, Qinghuangdao city & district & 6 \\
\hline Hua Li [9] & 2015 & 2378 & Hebei province & provincial & 5 \\
\hline Lei Qiao [16] & 2010 & 440 & a district, Beijing & district & 8 \\
\hline Xiuyun Sun [15] & 2011 & 801 & Chongwen district, Beijing city & district & 4 \\
\hline Xiaoqin Feng [31] & 2015 & 1990 & Lvliang city,Shanxi province & municipal & 5 \\
\hline Lixia Ma [19] & 2014 & 610 & Ningxia province & provincial & 6 \\
\hline Yine Zhang [12] & 2016 & 610 & Xingqing district and Zhongning county,Ningxia province & district & 6 \\
\hline Yaru Qin [1 1] & 2015 & 303 & Zhongning county, Ningxia province & district & 5 \\
\hline Can Liu [10] & 2016 & 304 & Baohe district, Hefei city & district & 6 \\
\hline Ying Deng [22] & 2015 & 2373 & Sichuan province & provincial & 5 \\
\hline Yajun Meng [32] & 2014 & 301 & Huangshigang district, Huangshi city & district & 4 \\
\hline Chuanhua Yu [17] & 2016 & 1800 & Hubei province & provincial & 5 \\
\hline Tianjing He [18] & 2016 & 1724 & Hubei province & provincial & 5 \\
\hline Donghui Jin [21] & 2015 & 2088 & Hunan province & provincial & 6 \\
\hline Xiaohong Zhou [45] & 2015 & 303 & Xiacheng district, Hangzhou city & district & 6 \\
\hline Kaixu Xie [46] & 2014 & 1800 & Tongxiang city, Zhejiang province & municipal & 7 \\
\hline Yan Xu [20] & 2015 & 1495 & Jiangxi province & provincial & 6 \\
\hline Ling Chen [47] & 2015 & 302 & Haicheng district, Beihai city & district & 6 \\
\hline
\end{tabular}

$13.30 \%$ in Ningxia Province [12], 25.00\% in Hefei City [10] and $26.40 \%$ in Sichuan Province [22]. It is worth noting that $6.90 \%$ of the hypertensive floating patients have not realized the fact that they could use the community health management service without any charge [22].

\section{The gender difference in hypertension among floating population}

According to the national survey about hypertension in China, the prevalence of hypertension in males (31.2, 95\% CI 30.1-32.4\%) is higher than that in females (28.0, 95\% CI 27.0-29.0\%) [23]. Similar results can also be found in most of the included studies about floating population $[6,10,12,16,17,19,20,22,24]$. In addition, Hua Li's study also shows that the prevalence of hypertension in males is higher than that in females in floating population under 50 years old, but it reverse in floating population over 50 years old [9]. From a physiological perspective, endogenous sex hormones may play a certain role, and high level of oestrogen can help reduce the risk of hypertension in females [25]. Because the floating group is relatively young, and the average age of them is less than 40 years old [4], so the prevalence of hypertension in male floating population is higher than that in females. However, Yaru Qin's study shows that the difference between prevalence of hypertension among men and women is not statistically significant [11].

\section{The age difference in hypertension among floating population}

Increased age is an important risk factor of hypertension. According to a national survey, the age-specific prevalence of hypertension is $13.0 \%$ in young people (aged 20 to 44 years old), 36.7\% in middle-aged people (aged 45 to 64 years old), and $56.4 \%$ in elderly people (aged $\geq 65$ years old) [26]. Although the floating population group is mainly composed of young people, the prevalence increases with ages, too. In Donghui Jin's research [21], the prevalence of hypertension in floating population aged under 35 years old is $5.21 \%$, and it increases to $28.39 \%$ in older group aged $\geq 35$ years old. Similarly, Xin Meng's research shows the prevalence of hypertension in floating population group aged under 40 years old (14.2\%) is significantly lower than that in older group aged $\geq 40$ years old (40.8\%) [24]. 
Table 2 Summary of the prevalence of hypertension in included studies

\begin{tabular}{lll}
\hline First author & Study area & Prevalence \\
\hline Xin Meng [24] & Jinlin province & $21.37 \%$ \\
Tao Li [14] & Akesu city, Xinjiang province & $25.31 \%$ \\
Xiaofei Wu [13] & Kashi city, Xinjiang province & $8.00 \%$ \\
Qian Zhou [6] & Inner Mongolia province & $36.50 \%$ \\
Chunxia Liu [7] & Haigang district, Qinhuangdao city & $28.05 \%$ \\
Chunxia Liu [8] & Haigang district, Qinhuangdao city & $27.00 \%$ \\
Hua Li [9] & Hebei province & $25.78 \%$ \\
Lei Qiao [16] & a district, Beijing city & $21.20 \%$ \\
Xiuyun Sun [15] & Chongwen district, Beijing city & $8.70 \%$ \\
Xiaoqin Feng [31] & Lvliang city,Shanxi province & $23.02 \%$ \\
Lixia Ma [19] & Ningxia province & $15.30 \%$ \\
Yine Zhang [12] & Ningxia province & $15.57 \%$ \\
Yaru Qin [11] & Zhongning county, Ningxia province & $7.30 \%$ \\
Can Liu [10] & Baohe district,Hefei city & $31.60 \%$ \\
Ying Deng [22] & Sichuan province & $17.40 \%$ \\
Yajun Meng [32] & Huangshigang district, Huangshi city & $19.93 \%$ \\
Chuanhua Yu [17] & Hubei province & $22.70 \%$ \\
Tianjing He [18] & Hubei province & $16.50 \%$ \\
Donghui Jin [21] & Hunan province & $16.70 \%$ \\
Xiaohong Zhou [45] & Xiacheng district, Hangzhou city & $16.17 \%$ \\
Kaixu Xie [46] & Tongxiang city, Zhejiang province & $13.67 \%$ \\
Yan Xu [20] & Jiangxi province & $16.80 \%$ \\
Ling Chen [47] & Haicheng district,Beihai city & $7.28 \%$ \\
\hline & & \\
\hline
\end{tabular}

\section{The risk factor of hypertension among floating population}

According to the global report on hypertension, unhealthy diet, harmful use of alcohol, lack of physical activities, excess weight and exposure to persistent stress are strongly related to hypertension [27]. Through the summary about relevant content in those selected literature, we choose the alcohol consumption and obesity as the major indicators of risk factors in floating population (Tables 3 and 4).

Guansheng Ma's survey about the condition of alcohol consumption in general population shows that the rate of drinking is $21.0 \%$ [28]. All the included studies show that floating population tend to consume more alcohol. And the drinking rate in Akesu City of Xinjiang Province even reaches $67.90 \%$ [14], which greatly exceeds the national level. In the comparison with local residents, floating group is also likely to have more alcohol consumption. The rate of drinking in floating population in Qinhuangdao City of Hebei Province is $66.33 \%$, which is higher than that in local residents (41.40\%) [29]. The same result can also be seen in Shanxi Province, where the general drinking rate in local residents is $30.10 \%$ [30], a little lower than that in floating population in Lvliang City of Shanxi Province (31.40\%) [31]. Moreover, the rate of drinking in floating population in Huangshi City (46.51\%) [32] is even much higher than that in middle-aged and elderly local people (30.8\%) [33], as well as male rural residents in Hubei Province (33.38\%) [34]. Their high-intensive work or bad dietary habit might be a potential reason for the high drinking rate.

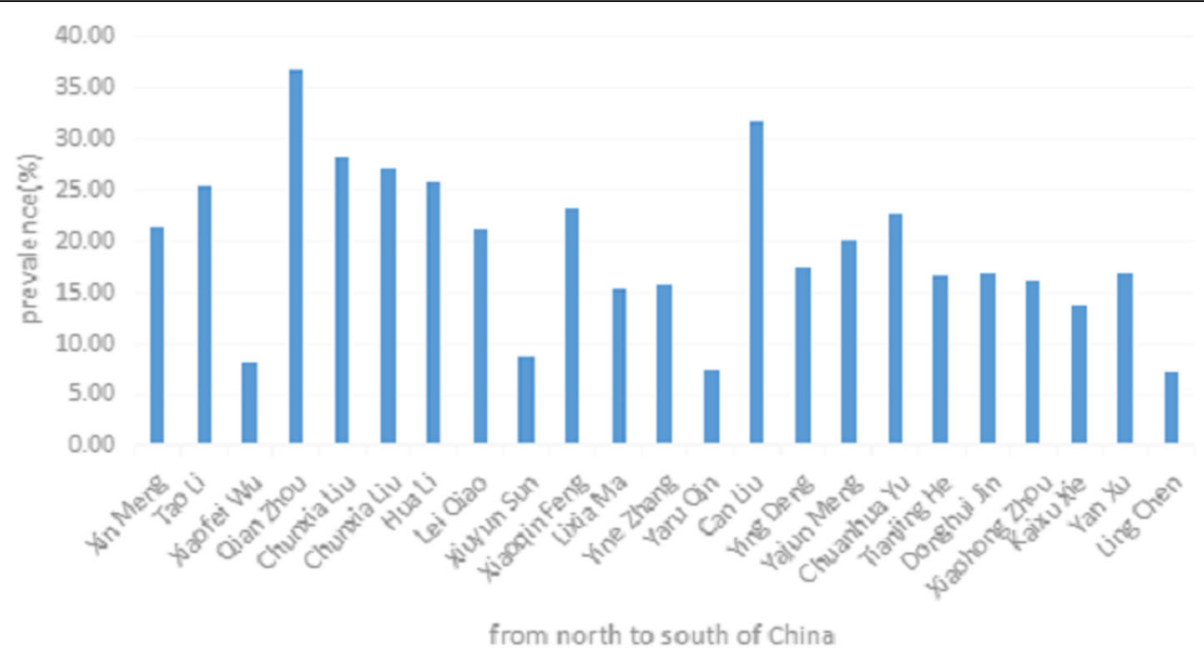

Fig. 2 Prevalence of hypertension in floating population 
Table 3 Drinking rate of floating population in some included studies

\begin{tabular}{lll}
\hline First author & Study area & Drinking rate \\
\hline Tao Li [14] & Akesu city, Xinjiang province & $67.90 \%$ \\
Chunxia Liu [6] & Haigang district, Qinhuangdao city & $66.33 \%$ \\
Xiaoqin Feng [31] & Lvliang city,Shanxi province & $31.40 \%$ \\
Yajun Meng [32] & Huangshigang district, Huangshi city & $46.51 \%$ \\
\hline
\end{tabular}

According to the national survey conducted in China, the rate of overweight is $29.3 \%(95 \% \mathrm{CI}, 28.5-30.1 \%)$, and the rate of obesity is $10.6 \%(95 \% \mathrm{CI}, 10.1-11.2 \%)$ [23]. In floating population, the overweight rate is $26.8 \%(95 \%$ CI,26.4-27.3\%), and the obesity rate is $4.7 \%$ (95\% CI,4.5$5.0 \%$ ) [4], both are lower than the level of general population. While Hua Li's study shows that the rates of overweight and obesity in floating population are 39.19 and $16.99 \%$ in Hebei Province [9], the results of most selected regional studies are close to the national level in floating population. Xiuyun Sun's study reveals that the overweight rate and obesity rate in floating population in Beijing are 26.10 and 5.90\% [15]. Xiaofei Wu's study shows that the $24.00 \%$ of floating population are overweight and $14.3 \%$ of them are obese [13]. The rate of overweight in Beihai City of Guangxi Province is $23.84 \%$ [35], and the rate of obesity in Hubei Province is $7.80 \%$ [18] in floating population. The probable reason is that the floating population is mainly composed of relative young people who are engaged in labour-intensive work, which could help them effectively prevent overweight and obesity.

\section{The disease management of hypertensive floating population}

Hypertension is an important public health problem all over the world because of its high prevalence and concomitant risk of cardiovascular and kidney disease $[35,36]$. And it has also been identified as the leading risk factor of mortality and the third cause of disability-adjusted life-years [37]. Therefore, it is a great responsibility for the government to guarantee efficient long-term treatment for hypertensive patients and help them keep blood pressure well controlled. The rates of

Table 4 Overweight and obesity rates of floating population in some included studies

\begin{tabular}{llll}
\hline First author & Study area & $\begin{array}{l}\text { Overweight } \\
\text { rate }\end{array}$ & Besity rate \\
\hline Hua Li [9] & Hebei province & $39.19 \%$ & $16.99 \%$ \\
Xiuyun Sun [15] & $\begin{array}{l}\text { Chongwen district, } \\
\text { Beijing city }\end{array}$ & $26.10 \%$ & $5.90 \%$ \\
Xiaofei Wu [13] & Kashi city, Xinjiang province & $24.00 \%$ & $14.30 \%$ \\
Ling Chen [47] & Haicheng district,Beihai city & $23.84 \%$ & $7.80 \%$ \\
\hline
\end{tabular}

awareness, treatment and control are significant indicators to evaluate government's function in the management system of chronic disease (Table 5).

According to Dongfeng Gu's study, the awareness rate of hypertension in general Chinese adults is $44.7 \%$, the treatment rate is only $28.2 \%$, and the control rate is $81.0 \%$ [38]. The floating population are rarely involved in the local management system of chronic disease, so their condition is always much worse. Lixia Ma's study shows that the awareness rate in floating population in Ningxia Province is $32.30 \%$, control rate is $40.00 \%$ [19], both lower than that of the general population. In the comparison with local residents, Qian Zhou's study in Inner Mongolia reveals that the rates of awareness, treatment are 44.20 and $30.20 \%$, both lower than the level of local residents in Hulunbeier City (58.70 and 44.20\%) [39]. Similar conclusion can also be seen in Sichuan Province, where the rate of awareness in floating population is $28.40 \%$ [22], lower than the level of local population within the province [40].

\section{Discussion}

There exists a large gap between current disease management situation and the ideally acceptable state through above analysis. Major reasons of the worse management condition include the following three aspects. Firstly, most of the floating population have to migrate every year to make a living, which is quite inconvenient for the community health care center or other health department to carry out long-term and continuous monitoring and intervention towards them. And due to their tremendous liquidity, they are always neglected by the basic public health service allocation system, which is mainly based on the number of residents within the jurisdiction to make the financial budget. In that case, the local primary health care centers don't have the motivation and capacity to provide service to floating population. Secondly, the number of floating population in China is still increasing rapidly, which would pose a great challenge to the hypertension prevention and management system. In 1990, the number of floating population in China was nearly 22 million, and then the size doubled in the five years from 1990 to 1995 [41]. By 2000, it had reached 121 million, representing $10 \%$ of China's total population at that time [42]. However, the supply capacity of health service in

Table 5 Management condition in some included studies

\begin{tabular}{lllll}
\hline First author & Study area & $\begin{array}{l}\text { Awareness } \\
\text { rate }\end{array}$ & $\begin{array}{l}\text { Treatment } \\
\text { rate }\end{array}$ & $\begin{array}{l}\text { Control } \\
\text { rate }\end{array}$ \\
\hline Lixia Ma [19] & Ningxia province & $32.30 \%$ & $\backslash$ & $40.00 \%$ \\
Qian Zhou [6] & $\begin{array}{l}\text { Inner Mongolia } \\
\text { province }\end{array}$ & $44.20 \%$ & $30.20 \%$ & $\backslash$ \\
Ying Deng [22] & Sichuan province & $28.40 \%$ & $\backslash$ & $\backslash$ \\
\hline
\end{tabular}


community health service centers, township hospitals, and other basic health institutions can not meet the floating population's requirements in a short time, so more practitioners and related facilities are in need. Thirdly, floating population are always known to be engaged in 3D jobs (dirty, difficulty, and dangerous), and they have to endure lower wages, and poor housing conditions [43, 44]. All these poor living factors could be harmful for their health. In order to finish the labor-intensive job, they have to spend more time and energy, and thus they don't have enough free time to care about physical health or receive health education and blood pressure management. Moreover, because of the slender income, they are also unable to enjoy timely health care service and effective medication treatment.

\section{Conclusion}

This review contains all the literature about hypertensive floating population in Mainland China. The major result is that the prevalence of hypertension in floating population is generally lower than that in general population and local residents in China, except for some regions. In addition, males and aging floating groups are more likely to suffer from hypertension. Compared with general population, the drinking rate in floating population is much higher, but the rates of overweight and obesity are roughly lower. Finally, the disease management of floating population cannot meet the requirements and still needs to be improved. So the major problem of floating population is focused on their unhealthy lifestyle (drinking) and deficient disease management.

The results indicate that the potential threat brought by hypertension in floating population is imponderable. To achieve the "primary health care for all" health strategic objectives, the relevant departments should undertake the responsibilities to care about the floating population. In order to satisfy the increasing health service need of floating population, some relevant effective measures and policies are urgent to be carried out.

Recommendations are as follows: Firstly, increasing the fund and facility support for public health service system so as to improve their service delivery ability and reduce medical burden of floating population. Secondly, in order to strengthen their health awareness and improve compliance to disease management, it is also necessary to enforce the health education and unhealthy lifestyle intervention towards floating population by health lectures or follow-up, including limiting alcohol consumption, enhancing physical exercise and maintaining a healthy weight.

\section{Study limitations}

The strength of this article is the complete inclusion of all published studies about the hypertensive patients in floating population of Mainland China, and it is the only review on this topic in the literature. The limitation of this study is the relatively small sample size in some researches.

\section{Acknowledgements}

I would like to give great thanks to my tutor, Professor Lingzhong Xu. In the process of composing the paper, he gives me a lot of academic advice and spiritual encouragement. In addition, I also want to appreciate Doctor Long Sun for his help in correcting the paper and data explanation.

\section{Funding}

The National Natural Science Foundation of China (No. 71673169).

\section{Availability of data and materials}

All the data and materials involved in this paper are from the published articles, and they are all available online.

\section{Authors' contributions}

LS integrated and analyzed the data regarding the prevalence of hypertension and risk factors in the floating population. My co-worker Dr. $L S$, Professor LX contributed to the data explanation, and were major contributors in writing the manuscript. All authors read and approved the final manuscript.

\section{Authors' information}

Lina Su (1990 -), female, research direction: social medicine and health management.

Long Sun (1985-), male, research direction: suicide and social medicine. Correspondent: Lingzhong Xu (1964-), male, research direction: health care management and health economy.

\section{Ethics approval and consent to participate}

This article is a review and doesn't involve animals and personal information survey, so the ethics approval and consent to participate are not applicable.

\section{Consent for publication}

This review doesn't contains any individual person's data, so the consent for publication is applicable.

\section{Competing interests}

All the authors declare that they have no competing interests.

Received: 12 December 2017 Accepted: 2 July 2018

Published online: 23 July 2018

\section{References}

1. National health and Family Planning Commission. "China population development report 2016" summary of the contents of [J]. of adolescent health. 2016;(22):90-91.

2. National Bureau of Statistics of the People's Republic of China. Statistical Communique on national economic and social development of People's Republic of China in $2015 \sim([4])[N]$. People's Daily. 2016-03-01(010).

3. Fu, Wu Jing, Wang Hongmei. The prevalence and risk factors of diabetes mellitus among floating population in Hainan province [J]. Chinese journal of Tropical Medicine. 2014;(10):1192-1196.

4. Bi Y, Wang L, Yu X, et al. Diabetes-related metabolic risk factors in internal migrant workers in China: a national surveillance study[]]. Lancet Diabetes Endocrinol. 2015;4(2):125-35.

5. Xu Y, Bi Y, Li M, et al. Prevalence, awareness, treatment, and control of hypertension in China: the China metabolic risk factor study[]]. Circulation. 2013;94(11):1058-64

6. Qian Z, Peiyu W, Yonggang $\mathrm{Q}$, et al. A cross-sectional study on hypertension among different floating population in Inner Mongolia J. Chinese J Hypertension. 2015;9:857-62.

7. Chunxia L, Xiangyu Z, Liang X. Investigation of common chronic diseases and its influencing factors among floating population in Harbor District of Qinhuangdao City[]]. Chin Preventive Med. 2015;16(8):642-4. 
8. Chunxia $L$, Xiangyu $Z$, Liang $X$, et al. Epidemiological prevalence of hypertension among migrant populations aged above 18 in Harbor District of Qinhuangdao City[J]. Chin J Health Educ. 2015;6:564-6.

9. Hua $L, Z e ~ C$, Junqing $Z$, et al. The morbidity and risk factors of main chronic diseases among employment floating population in Hebei Province[J]. Chin Prevention Control Chronic Dis. 2015;23(2):108-12.

10. Can $L$, Junrui $X$, Junqing $Z$, et al. Analysis of the prevalence and influencing factors of hypertension among floating population in Baohe District of Hefei in 2012 [J]. Chin J Prevention Control Chronic Disease. 2016;24(10):756-61.

11. Yaru Q, Jun $H$, Zhenhua Z. Analysis of risk factors of hypertension in floating population [J]. Chin J Public Health Manage. 2015;5:710-1.

12. Yine $Z$, Hailong $H$, Jianhua $Z$, et al. Health status of floating population and analysis of their direction of medical treatment in Ningxia disease surveillance center[J]. J Ningxia Med University. 2016;38(1):75-80.

13. Wu $X$, Jun $L$, Zhongmei S. Investigation on chronic diseases and risk factors of floating population in Kashi of Xinjiang in 2012 [J]. Bull Dis Prev Control. 2013(4):14-5.

14. Tao L. Investigation on hypertension and behavioral risk factors among Kazak floating population in Akesu city in 2012 [J]. Bull Dis Prev Control. 2013;(4):18-20.

15. Xiuyun S, Dongmei Z, Xuan L, et al. Survey on health status, demand, and utilization of community health Service in Floating Population of Chongwen District, Beijing[J]. Chin J Prev Control Chronic Dis. 2011:19(5):455-7.

16. Lei $Q$, Zhen $Y$, Xuhong $W$, et al. The prevalence of non-communicable diseases among the floating population in urban Beijing, China[J]. Chin J Prev Control Chronic Dis. 2010;18(2):111-4.

17. Chuanhua $Y$, Ruixia $Y$, Junzhe $B$, et al. Risk factors for hypertension and diabetes among floating population in Hubei Province: a cross-section survey[J]. Chin J Evidence-Based Med. 2016;8:891-6.

18. Tianjing $H$, Lan Z, Yumeng $T$, et al. The morbidities of main chronic noncommunicable diseases among the employed mobile population in Hubei province[J]. Chin J Prev Control Chronic Dis. 2016;24(3):175-8.

19. Lixia $M$, Jing $L$, Yanping $Z$, et al. An investigation of main chronic disease among migrant employees at surveillance sites of Ningxia in 2012[J]. J Ningxia Med University. 2014;36(6):669-73.

20. Yan $X$, Liping $Z$, Wei $Y$, et al. Hypertension prevalence and influencing factors in migrants, Jiangxi Province[J]. Modern Preventive Medicine. 2015;42(7):1179-82.

21. Donghui J, Qiaohua X, Huilin L, et al. Management of hypertension and diabetes mellitus among floating population in Hunan [J]. Practical. Preventive Medicine. 2015;22(10):1211-2.

22. Ying D, Jin Z, Kui J, et al. Analysis of hypertension morbidity among floating population of Sichuan in 2012[J]. Chin J Prev Control Chronic Dis. 2015;23(1):27-30.

23. Wang J, Zhang $L$, Wang $F$, et al. Prevalence, awareness, treatment, and control of hypertension in China: results from a National Survey[J]. Am J Hypertens. 2014;27(11):1355

24. Xin $M$, Wenyang $Z$, Yang $X$, et al. Correlation analysis of risk factors of hypertension among floating population aged 40 years and over[J]. Chin J Gerontol. 2015;4:1051-3.

25. Austin CE. Chronic and acute effects of oestrogens on vascular contractility[J]. J Hypertens. 2000;18(10):1365.

26. Gao $Y$, Chen $G$, Tian $H$, et al. Prevalence of hypertension in China: a crosssectional study[J]. PLoS One. 2013;8(6):e65938.

27. Organization W H. A global brief on hypertension : silent killer, global public health crisis: world health day 2013[J]. 2013.

28. Guansheng $M$, Danhong $Z$, Xiaoqi $H$, et al. The drinking prevalence of people in China[J]. Acta Nutrimenta Sinica. 2005;27(5):362-5.

29. Lina $W$, Hua $L$, Li C, et al. The investigation of alcohol consumption status in adult residents living in Hebei Province[J]. Modern Preventive Medicine. 2007:34(2):279-83.

30. Yunong Z. Investigation and analysis of related risk factors of adult chronic diseases in Shanxi Province in 2004[D]: Shanxi Medical University; 2006.

31. Xiaogin F. Epidemiological characteristics of hypertension in floating population in Lvliang[J]. Chin J Integrative Medicine on Cardio/ Cerebrovascular Disease. 2015:1:125-7.

32. Yajun $M$, Yan $C$. Investigation on risk factors of chronic diseases among employed floating population in Huangshi port of Huangshi in 2012[J]. Preventive Medicine Tribune. 2014;7:493-6.
33. Jianjun C, Qingjun Z, Yang $L$, et al. The prevalance study on behavior risk factors of the middle and old aged people in some area of Hubei Province, China[J]. Medical Journal of Wuhan University. 2005;26(4):497-501.

34. Tianduo L, Hongxian Y. Study on drinking patterns and related factors in rural population[J]. Chinese Journal of Social Medicine. 1988;6

35. He J, Whelton PK, He J, Whelton PK. Epidemiology and prevention of hypertension[J]. Med Clin N Am. 1997;81(5):1077-97.

36. Whelton PK. Epidemiology of hypertension[J]. Lancet. 1994;344(8915):101.

37. Ezzati M, Lopez AD, Rodgers $A$, et al. Selected major risk factors and global and regional burden of disease[J]. Lancet. 2002;360(9343):1347.

38. Dongfeng G, He J, Xigui W, et al. Prevalence,awareness,treatment and control of hypertension in Chinese adults[J]. Chin J Prev Med. 2003:37(2):84-9.

39. Tingting S, Pengcheng D, Zixin W, et al. Awareness, treatment, control of hypertension in Hulunbeier and hypertension-related KAP in patients[J]. Food and Nutrition in China. 2011;17(6):78-82.

40. Xinyin X, Ying D, Kui J, et al. Population health and the epidemic status of key chronic disease in Sichuan Province[J]. Dis Surveillance. 2017;32(1):6-8.

41. Liang Z, Ma Z. China's floating population: new evidence from the 2000 census[J]. Population Dev Rev. 2004;30(3):467-88.

42. China National Bureau of Statistics. Characteristics of Chinese rural migrants: 2000. Beijing: News Release; 2001.

43. Feng W, Zuo X, Ruan D. Rural migrants in shanghai: living under the shadow of socialism[J]. Int Migr Rev. 2002;36(2):520-45.

44. Yang Q, Guo F. Occupational attainments of rural to urban temporary economic migrants in China, 1985-1990[J]. Int Migr Rev. 1996:30(3):771-87.

45. Xiaohong Z, Shengjun X, Qi Z, et al. An analysis on the prevalence and risk factors of non - communicable diseases among immigrants in Xiacheng district in Hangzhou city[J]. Zhejiang J Prev Med. 2015;12:1202-5.

46. Kaixu $X$, Yabin $H$, Lingli $C$, et al. Investigation and analysis of chronic disease and its risk factors of floating population in Tongxiang [J]. Chin J Health Stat. 2014;31(5):882-4.

47. Ling $C$, Deren $W$, Yongmei $Y$, et al. Investigation on chronic diseases and risk factors of floating population in Beihai District of Haicheng in 2012[J]. Prev Med Tribune. 2015;3

\section{Ready to submit your research? Choose BMC and benefit from:}

- fast, convenient online submission

- thorough peer review by experienced researchers in your field

- rapid publication on acceptance

- support for research data, including large and complex data types

- gold Open Access which fosters wider collaboration and increased citations

- maximum visibility for your research: over $100 \mathrm{M}$ website views per year

At $\mathrm{BMC}$, research is always in progress.

Learn more biomedcentral.com/submissions 